\title{
Jorge Isaacs y la Realidad de su Espíritu
}

$\mathbf{J}^{\mathrm{o}}$ ORGE Isaacs revive ante nuestros espíritus un largo y convulsivo período de la historia nacional. Intelectualmente representó las particularidades más notables del movimiento romántico. Como hombre, fué víctima de las estrechas circunstancias económicas de ese tiempo. Como caudillo político, y como militar, intervino en algazaras y revoluciones, igual que cualquier hijo de trópico, impulsado por fanatismos de partido. Pero si el fusil que se echó al hombro en plena juventud, y cuyos fogonazos alumbraron trágicamente el campo de las discordias civiles, cayó de sus manos oscuramente, como que no había sido más que un instrumento de nuestra demencia fratricida; si de sus trabajos y penalidades sin término en busca del bienestar material, sólo resta una crónica dolorosa, exornada por bravos lances de heroísmo conquistador, que nimba su nombre con la mística predestinación de la pobreza y lo emparenta con don Miguel de Cervantes, y con el fruncido y cogitabundo Alighieri - buscadores del pan bajo el luminoso extravío de su genio-, en cambio de su actividad literaria nos queda un libro grande y eterno, que vence a todas las empresas de su vida, y que le ha conferido renombre universal. María es algo más que una obra literaria. Es el código sentimental de una raza, es el breviario amoroso de un pueblo, es el espejo fidelísimo de una comarca bella, es un vivo y exacto manual de costumbres regionales, es un sabroso archivo de frescos decires y donairosos modismos, un noble modelo de patriarcales costumbres, una soleada galería de tipos montañeses y de geórgicas doncellas, pintados unos y otras, al aire libre, bajo el pabellón de la selva. Pero, sobre todas estas cosas, esa novela, como los libros de caballerías, 
es una alta y permanente lección de idealismo, un inspirado texto de platónicos fervores y un tratado de amor purísimo, al que la misma muerte, y los presagios fúnebres que allí abundan, le otorgan ese sobrehumano temblor que hace trepidar la mano de los místicos, al tratar del misterio final con palabras que alumbran por sí solas la noche de los sepulcros.

Una curiosa consideración me ha asaltado siempre al recorrer las páginas de María. ¿Cómo pudo salir de este medio ambiente tropical una novela tan casta y pudibunda, a cuyo lado, y esto sería fácil comprobarlo, aparecen como demasiado libres algunos relatos de la literatura religiosa? ¿ No hay en los deliquios ascéticos de la poesía sagrada acentos demasiado humanos, que no por su intención alegórica, dejan de recordar inexplicablemente las afecciones terrenas? Pues ni siquiera esto se advierte en María. Todo es allí puro, todo es allí inmaculado. En estos días de la líbido freudiana y del complejo sexual, ese libro parece escrito sobre la rodilla de los ángeles. Uno cualquiera de los ademanes y actitudes que realiza la heroina pudiera servir para que un artista representara al Pudor. ¿Recordáis aquel pasaje en que María, con los pies descalzos, corta flores? Apenas advierte que es observada por el enamorado adolescente, cae de rodillas y se cubre con el bordado pañolón. ¿ Hay en la literatura universal un arranque más entrañablemente femenino que éste? La gracia, la inocente coquetería y la vergüenza se suman en ese movimiento instintivo, donde resplandece la suprema dignidad de que el cristianismo revistió a la mujer.

"Amor sacro" llamó el anónimo escultor a una de las figuras en relieve que adornan el trono Ludovici. Es una dama sentada delante del pebetero donde quema granos aromáticos. Desde la frente hasta los tobillos la envuelve un manto que se ajusta al cuerpo en pliegues de perfección matemática. Sólo quedan visibles el austero perfil y los pies oprimidos por las sandalias. Como símbolo del decoro femenino nada nos legó la antigüedad arcaica comparable a esa figura. iCómo contrasta la rígida majestad de ese manto con los cuerpos desnudos donde cada detalle anatómico constituía para aquellos idólatras de la vida, una suprema aspiración hacia la belleza inalcanzable! Pero yo digo que la dama velada de la antigüedad es menos pura que la virgen americana, porque aquélla realizaba un simple acto de compostura doméstica, sin que hubiese un principio más alto que iluminara sobrenaturalmente la belleza de su conducta; en tan- 
to que ésta, al ocultar los pies desnudos, rendía tributo a la perfección moral de la doncella; se anticipaba a la suprema majestad de la madre; defendía con antelación la pureza del hogar y ponía a salvo las tradiciones de su raza. Y no penséis que todo esto se realizaba a nombre de las conveniencias biológicas, como pudiera suponerlo un profesor de psicología contemporánea. No. La virtud que se cubre los pies es la misma que corona a las doncellas en el circo; la misma que viste de blanca toca centenares de frentes inmaculadas; la misma, en fin, que hace que la tierra suba hasta el cielo, cuando se produce el héroe, o que el cielo baje hasta la tierra, cuando aparece el santo.

$Y$ sin embargo, la mezcla de sangre, la vida de los campamentos y las incitaciones de la zona tórrida hacían esperar de Isaacs una novela de tumultuosa sensualidad, o, por lo menos, una cálida evocación de su paisaje, una pintura meridiana y luciente de su tierra, hija predilecta del sol, favorita de las brisas océanicas, inmensa flor de verdura, abierta sobre los campos de la patria, y de cuyo cáliz se elevan, como pistilos gigantescos, los troncos de las palmeras. Vivió Isaacs en este Valle cuando más agudas y persistentes son las impresiones de los sentidos. Aquí despertó su pubertad, aquí se hizo hombre, aquí sintió las inexplicables melancolias en que se refugia el instinto desorientado por las primeras experiencias de la vida. Su precocidad para sentir debió ser extraordinaria, ya que la mezcla de razas sensibles e imaginativas que había en él, lo convertía de hecho en un instrumento infinitamente sonoro al roce de las emociones. Su producción literaria fué un poco tardía. Las primeras épocas de su vida debieron ser de reserva, de acumulación, de atesoramiento. Hijo de padres acaudalados que, a la postre, vinieron a convertirse en especie de hidalgos campesinos, Isaacs niño debió de vivir en entrañable unión con la naturaleza que lo rodeaba, y al mismo tiempo, en una incomparable libertad de espíritu que le permitía entregarse a todos los caprichos de una imaginación exuberante. Le vemos recorrer a caballo estas pampas como un pequeño centauro cuyos pies permanecían hundidos en la tierra, pero en cuyo pecho ya empezaban a reflejarse las constelaciones. Le vemos mezclarse a las faenas del campo, participar de los trabajos agrícolas, departir con arrieros montañeses, juntando a las voces castizas, aprendidas en la casa, los frescos, sonoros y expresivos vocablos del habla regional. Le vemos armado de la escopeta, y en medio de la jauria impaciente, haciendo 
numerosas victimas entre las aves y animales de su arbolado fundo, para descansar luego a la orilla de las cascadas, que bajan de la sierra vestidas de encaje, como las doncellas que se dirigen a la boda. Le vemos, finalmente, entrar en la biblioteca paterna, cuyo piso de tablas resuena al choque de las espuelas que no alcanzó a desatarse el señorito feudal, y embeberse en la lectura de uno de esos autores tan de boga entonces, como el señor Chateaubriand, cuya afiebrada sensibilidad respondía simpáticamente al temperamento vibrante del adolescente caucano. Entrada la noche, recostábase el joven Isaacs en la baranda del corredor que daba sobre el Valle. Las tempestades del Pacífico, destacando el perfil de la cordillera remota, iluminaban la llanura con relámpagos momentáneos. Un arbusto, literalmente cubierto de luciérnagas, semejaba una llama pálida en la cual se estuviesen quemando todos los aromas de aquella noche tropical. El río cercano concertaba su serenata de guzlas árabes y de tamboriles indígenas, en tanto que la selva, mecida intermitentemente por el viento de la noche, interrumpía aquella música para dejar que luego se desborlase sobre el campo. $Y$ si eran gratos los rumores, aun eran más gratos los silencios, porque entonces, sobre la mudez de la tierra, caía más limpia la claridad de las estrellas que parecían agolpar sobre el valle toda la riqueza de las noches americanas.

¿Qué hacía el adolescente, en medio de aquel paisaje lánguido adormecido en su propia fecundidad, como las hembras de numerosa prole, $\mathrm{y}$ a veces enervante, como el hálito que sube de los pantanos florecidos? Pensaba en la prima lejana que vendría a vivir en ese mismo hogar, y cuyo rostro le era conocido por referencias y fotografías. Un perfil de procedencia judía, una cabellera repartida en dos trenzas, una crucecita de coral en el cuello, ¡ nada más!; pero eso era suficiente para encender la imaginación del niño, como lo fué en Dante el encuentro con una criatura de nueve años, para que mucho tiempo después el sombrío enamorado fuese a golpear en las puertas del Paraíso. La prima no vino al Valle, pero Isaacs conservó ese recuerdo en su corazón. La semilla que el pájaro deja caer en la tierra origina un bosque. Un solo golpe rompe y conmueve extensas capas atmosféricas. De igual manera, una emoción o una idea depositadas en el alma cuando ésta es más sensible a las fecundaciones interiores, se transforman, a la postre, en todo un sistema de pensamientos o.de sensaciones que, inadvertidamente, llegan a la época de si perfecta madurez. Cuando Isaacs imaginó su novela, la imagen de 
María había crecido y se había embellecido en su memoria. Por uno de esos misterios que presiden a la creación intelectual, fué padre, novio y esposo de una misma mujer. La concibió en su cerebro, la amó en su corazón, la poseyó en la muerte. A semejanza de esas semillas que germinan dentro de un vaso, y se desarrollan, hasta que las raíces de la planta alli encerrada terminan por romper el cristal, la imagen de María, que originariamente no había sido más que una reminiscencia juvenil, acabó por hacer estallar el corazón del poeta, quien ya no pudo soportar más el peso de esa mujer, que se había hecho inmortal dentro de su espíritu.

¿Por qué razón, vuelvo a preguntarme, la María es obra de tan alta delicadeza moral, habiendo nacido bajo la influencia de un clima propicio a la exaltación de todos los instintos biológicos, entre las concitaciones de una naturaleza lujuriante? Es preciso buscar la explicación en la ascendencia inglesa y hebrea del escritor. Ya uno de los contertulios de "El Mosaico" había señalado afinidades con la poesía inglesa en algún poema de Isaacs. $Y$ así es, con efecto. Esa sinceridad en el sentimiento; esa lealtad en la expresión, sin afeites retóricos y dirigida directamente al objeto que desea pintar; esa emoción casi religiosa ante la naturaleza; ese suave panteísmo idealista que campea en sus páginas descriptivas, todo eso le vino de los bardos ingleses, por el camino de la sangre, y lo emparenta espiritualmente con los llamados poetas "lakistas", espíritus meditabundos que alzaron en la región de los lagos cátedras ambulantes de filosofía platónica. De otro lado, su ascendencia judía, de la que se mostraba orgulloso unas veces, y en otras dolorido, le había dado el tono elegíaco, la predisposición para las lágrimas, el amor por las grandes metáforas, el vivir errabundo, lamentando una patria perdida para siempre, y el culto sagrado y patriarcal de la mujer.

No copia Isaacs los aspectos esplendorosos del medio físico en que se desarrolla su novela. Busca, por el contrario, los tonos crepusculares, los momentos en que la naturaleza se recoge sobre sí misma, y parece poblada de sombras vivientes que hablan a media voz. Las horas de la tarde lo conmueven profundamente; horas "del perfecto aroma", como dijo arrobadoramente Rafael Pombo, tienen sobre su espiritu una eficacia religiosa. Recordad aquella imponente sinfonía descriptiva que comienza: "Una tarde, tarde comorlas de mi país, engalanada con nubes de color de violeta y lampos de oro pálido, bella como María, bella y transitoria como fué ésta para mí"... 
Hay aquí algo más que una serie de palabras artisticamente combinadas: hay un acorde perfecto entre la expresión y el sentimiento del paisaje. La voz está modulada de acuerdo con la emoción del himno. Muchas páginas del libro son largos "nocturnos", bocetos al carbón que no impiden ni el vigor, ni la sobriedad del trazo. A este respecto, los capítulos sobre el Dagua son sencillamente magistrales. Muy pocos los igualan en América. La salvaje soledad del lugar, la selva gigantesca, los peligros y asechanzas del río, la patética miseria de los seres que habitan en las orillas de aquella corriente encajonada, y, sobre todo, esa canción de los bogas, que es uno de los toques más punzantes de la novela, todo respira verdad, pero verdad trágica, y alta y solemne poesía.

En esa descripción van parejas la magnitud de aquel antro, verdadero vórtice andino que conserva todavía los fragores del desastre geológico que le dió origen, y la desesperación del poeta, incapaz de vencer los obstáculos materiales que opone, a su esperanza, aquella corriente desenfrenada, que en vez de humana vía de comunicación, semeja el cauce de la muerte, labrado bajo una bóveda de rocas. Allí está nuestra Américá intacta, nuestra América desierta, en su trágica realidad humana, en su duro interrogante cósmico. Isaacs habitó en el fondo de aquel largo y hervoroso cráter; fué huésped de aquel tajo adusto, abierto por la tempestad, alumbrado por el relámpago, batido por las aguas. No sólo vivió en aquel infierno de piedra, sino que allí le vino en voluntad concebir y escribir su libro, menos afortunado en esto que el desterrado florentino, quien pudo al menos disfrutar de las auras terrestres al componer su poema. Isaacs, no. A1 golpe de las picas que hendían aquellos muros de granito; al estampido de la pólvora que descuajaba enormes bloques compactos, los cuales, al interrumpir el curso del río, hacían que desbordase la corriente buscando nuevos cauces a su furor; entre el retumbo de los árboles derribados, cuyo descenso abría claraboyas de luz sobre ese valle subterráneo; en el fondo de aquel negro país de las serpientes y de los tenaces y zumbadores insectos, que traían el desvelo y la calentura, allí fué escrita la novela, alli vino al mundo María. ¡ Citrioso destino de todas estas criaturas inmortales! Beatriz nació en el destierro; Dulcinea, en un calabozo; la virgen americana en un abismo de los Andes. Sólo que nuestro poeta sacó a su serafín de entre las llamas y lo condujo a un paraíso de palmeras. Pero antes de verificarse ese tránsito, iqué dura, qué angustiosa, qué trágica la 
suerte de Isaacs! Hay que imaginárselo en aquel desfiladero que desemboca en el Océano, sentado, por la noche, delante de una rústica mesa, sudoroso y transido de emoción ante el papel sobre el cual caen, continuamente, las mariposas que hallan muerte en la lámpara de petróleo. ¿Pudo suponer ese inspector de caminos y capataz de cuadrillas humanas uncidas al barreno y a la pica, que aquellas páginas escritas muchas veces entre el canto de los bogas y las procacidades de los peones, iban a quedar como documento y expresión de la sensibilidad de una época, y a ser protocolizadas junto con aquellas que narran los amores de Pablo y de Virginia, o la muerte de Atala? Cómo hubiera sonreído desafiadoramente el oscuro burócrata que era entonces Isaacs, al entrever esta gloria futura de su nombre, y al tener conciencia de que a esa patria ingrata le estaba abriendo dos caminos: uno, para vincularla comercialmente con el mar, y otro, para ponerla en contacto con la gloria de su genio.

A su ascendencia judia hay que atribuir, en buena parte, su constante vagar, que no le dió reposo ni cuando descansaba en la muerte, pues fué necesario desenterrar sus huesos para llevarlos a una tierra adoptiva de su corazón, que él había cantado en estrofas sonoras y onduladas como los ríos. Antioquia le dió tema para sus mejores versos. "La tierra de Córdoba" es la más fresca, inspirada e importante de sus poesías, no obstante que al juzgar la obra de España en sus colonias, y la obra de la civilización cristiana en la Península, la musa que tan graciosamente venía cantando las mieses y los ganados, abate el vuelo hasta quedar enzarzada en los sectarismos y prejuicios históricos de la época; y, creyendo manejar el látigo de Juvenal, sólo consigue rendir tributo a la demagogia nacionalista que por aquel entonces sofocaba los ánimos. Pero, hecha esta salvedad, su canto a Antioquia inspira amor filial, y cierto egoísmo de raza, muy justificado; porque es necesario advertir que Isaacs creía a ciegas en el origen semítico de los antioqueños, en quienes no reconocía ningún rasgo, huella o indicio de tradición ibérica. A tiempo que los demás pueblos conquistados por España le parecían, según sus propias y desventuradas palabras, "sobra ruin del hierro, de la mita y de los tributos", consideraba al núcleo social de Antioquia como una porción incontaminada de Israel, $y$, enlazando hechos históricos, llegó a lamentar, igual que se tratase de una desgracia personal, la salida de los árabes de España. El atavismo judío transformaba, pues, su visión de la patria en cierto celo de tribu o de he- 
redad privilegiada, el cual arraigaba en las excelencias de la sangre, $y$, hallando motivo de orgullo en las grandezas pasadas, lo tenía de queja y de lloro al considerar las persecuciones presentes.

Pero no pudo ser Antioquia el lugar de quietud para su existencia contradictoria. Conservó, eso sí, durante toda su vida, los más vivos y cariñosos recuerdos de esa tierra, donde en hora inolvidable había sido coronado por el estruendo de una victoria militar, tan breve como inútil, $\mathrm{y}$ donde es posible que hubiese amado mujeres que le recordaban a las hijas de los Patriarcas. Allá estaba, además, aquel selvoso y resonante Río Moro, a cuya orilla sintió, más que nunca, la miseria de su destino, y de cuyos árboles colgó el arpa enlutada, para memoria de su destierro y de su cautividad.

La fatalidad de su casta hizo que su vida vacilara entre el apego profundo y sentimental a la tierra, y la necesidad de buscar siempre el bienestar económico en comarcas extrañas. Hubo en él un desterrado perpetuo, y, al mismo tiempo, una especie de patriarca montañés, deseoso de vivir entre gentes sencillas y laboriosas, entre campesinos honestos, entre mujeres limpias y cristianas. No lo consiguió nunca, porque el patrimonio familiar sufrió grandes quebrantos en manos de su padre, hidalgo despejado y elegante de quien nos ha dejado inolvidable semblanza. Tuvo, pues, que abandonar aquella "casa de la sierra", que todos tenemos en la memoria, y donde las aguas cristalinas, como las fuentes de los palacios árabes, comentan todavía los amores de su dueño. ¡ La casa de sus padres! Qué pintura tan detallada y tan fresca nos ha dejado de ese solar campesino, centro de atracción de toda la novela, y verdadero personaje de la obra, ya que Isaacs lo anima y sensibiliza todo con el poder comunicativo de su estilo. Allí vivió el poeta los mejores años de su vida, como niño mimado de una sociedad doméstica donde la esclavitud misma era llevadera, porque la suavizaba el sentimiento cristiano de la vida. La María no es más que una serie de cuadros patriarcales, una pura y tranquila égloga tropical, en su parte descriptiva, y un poema de la vida campestre que sólo al final se entenebrece, como esas tardes de nuestros climas, que comienzan vestidas de luz y acaban rasgadas por el relámpago.

Los personajes de la obra a quienes el novelista extrae de la cantera popular, son buenos y serviciales; aquellos que proceden de las clases acomodadas, gentiles y caballeros; y aun los mismos anima- 
les parece que participan de la nobleza de sus dueños. Contemplado a la luz de nuestros días, el libro de Isaacs refleja una época de venturosa tranquilidad social. Es cierto que los trastornos políticos y las guerras civiles, con su séquito de consecuencias, constituian un verdadero flagelo para el país. Dejar los bancos de la escuela a fin de acudir a los campamentos; empobrecerse de un día para otro; vivir bajo la amenaza de los guerrilleros y salteadores, e ignorar el sistema de vida política que regiría a la mañana siguiente, no era cómodo ni tranquilizador. Pero el régimen familiar no había sufrido menoscabo; el campesino era leal, el patrón caritativo y generoso, los servidores comedidos, así fuesen esclavos. Reinaba la honestidad de las costumbres, la fecunda bienandanza en los campos, el estudio y la honradez en las ciudades. La amistad era un culto, y el amor una devoción casi mística. Al anecdotario sentimental de América han pasado las novias de José Eusebio Caro, de Arboleda, de Gutiérrez, González de Vergara y Vergara, de Fallon, y no digamos la de Isaacs, que subió a darse la mano con Julieta y con Beatriz, en el cielo de los poemas bienaventurados. El amor por las bellas letras reconciliaba los espíritus más opuestos en creencias religiosas o en convicciones políticas, y la generosidad intelectual, sin sombra de envidia ni de emulaciones, era uno de los rasgos heroicos de la época. La gloria de Isaacs surgió de un cenáculo literario, y catorce patricios, entre los cuales había presidentes de la república, tratadistas de ciencias filosóficas y sociales, tribunos de fama continental, historiadores, novelistas y poetas, se conmovieron al escuchar unas estrofas románticas que habrían perecido, con algunas excepciones, entre el fárrago sentimental de la época, si María no les hubiera proyectado su resplandor. Pero es que los caballeros de "El Mosaico" advirtieron en Isaacs a un hombre de sensibilidad cristalina y de caudaloso temperamento. Eso bastó para cautivarlos. ¡Así éramos en 1860 !

Lo doméstico y patriarcal de ese ambiente está reflejado en la María con abundancia de detalles, con extraordinaria fidelidad de colorido. La novela carece de una acción exterior dominante; no juegan en ella personajes de condición excepcional, ni las descripciones del ambiente son pintura de parajes exóticos. Todo se reduce a unos cuantos sucesos caseros, y a hechos y circunstancias de ocurrencia habitual en las residencias campestres. Hay; además, un idilio intermitente, que si le infunde su tono sentimental y su intensidad lí- 
rica a la obra, no constituye, con propiedad, el cuerpo de la novela, que en las tres cuartas partes de su extensión, es un lienzo de trazo realista, una ancha galería descriptiva. ¿De dónde, entonces, el innegable interés que despierta, las patéticas emociones que suscita, la indefinible nostalgia que en las almas apasionadas deja esa historia sencilla, que termina en un cementerio agreste, como la única calle de las aldeas felices, y comienza con un diálogo en un jardín, como la primera mañana del mundo? Creo que el secreto reside en la minuciosa exactitud de las observaciones, que en nada se apartan de lo natural, hasta el punto de poderse afirmar que en la María, no hay línea ociosa, es decir, rasgo que no corresponda a la realidad objetiva. Pero si la pintura de los seres exteriores es verídica, la de los sentimientos y pasiones no lo es menos. La novela toda, desde este punto de vista, es un documento autobiográfico de sinceridad irrecusable. Isaacs -y al nombrar al autor hay que entender que se trata del protagonista- quiso confesarse en voz alta, según el estilo de la época, y darle al lenguaje la trémula ansiedad de los desgarramientos interiores. Sus instrumentos de análisis son de un alcance prodigioso. No dejan escapar ni la más leve sensación sin traerla, agrandada, a la superficie del lente. Pero lo que hay de admirable en este romántico es lo franco y espontáneo de su pasión. Rehusa ponerse delante del espejo para consultar la actitud más adecuada a su melancolía. En Isaacs el sentimiento brota de las raíces de su vida, y lo expone con diafanidad tal, que asi como ciertos ríos dejan ver las arenillas del fondo, cada palabra de su novela descubre las profundidades de su espíritu o las congojas de su existencia. La literatura es la expresión de su vida, la realidad misma de su alma, de modo que si no hubiesen ocurrido las escenas que describe en la novela, y si prescindimos de considerar a Isaacs como el hombre apasionado y congojoso que sabemos, es muy posible que la María, como obra literaria, no existiera, porque ni la simple intuición de los sucesos, ni las fuerzas de la imaginación, ni la sola virtud del estilo, reemplazan a la vida, ni pueden poner en una ficción de la fantasía ese temblor de humanidad que sólo se advierte en obras que han nacido directamente del choque de la existencia con la sensibilidad del genio.

Si no existe en la heroína de Isaacs más que una vaga presunción histórica, bien pudo el poeta haber creado esa figura mezclando, en una fisonomía ideal, rasgos verdaderos de mujeres distintas, o 
incorporando al ambiente de su Valle el recuerdo de la prima distante, o, de acuerdo con algunos pintores del Renacimiento que procedian "conforme a cierta idea", haciendo que encarnase, en una imagen de singular hermosura, la realidad de un amor que no había encontrado en la tierra objeto digno de su grandeza, o recipiente humano capaz de contenerlo. E1 arte posee, muchas veces, sentido vindicativo. El genio realiza, en la esfera de las ideas, lo que la vida le niega en el orden de las posibilidades humanas. El espíritu, herido en la tierra, traslada su actividad al reino bienaventurado donde el amor es tranquilo, la amistad firme, el pensamiento puro, la bondad constante y la belleza inalterable. Allá fué imaginada María. Efectivamente, al estudiar por separado cada uno de los personajes del libro se advierte que en la creación de esa figura, y sólo en ésa, concurren rasgos que el poeta tomó de su propio espíritu, y contornos que hubo de prestar a un arquetipo de categoría superior. En cambio, al dibujar las otras criaturas que por allí discurren, no sobrepasó el escritor los linderos humanos, ni fué, en la intención expresiva, más allá de los cánones realistas. Maria, por el contrario, es toda idealidad y toda ensueño. Al perder su identidad anecdótica, se convirtió en el símbolo puro de la pasión. Es algo más que una vida: es una idea realizada por el arte. Para estudiarla y comprenderla no es necesario seguir su biografía temporal, sino descifrar las claves eternas del corazón humano. María es el amor que nace, destella plenamente, y se extingue. En ella se realiza el cielo cabal de la existencia cósmica. Es elemental como las grandes fuerzas de la vida; eterna como el sentimiento que en ella reside; breve y transitoria como el tiempo que limita su voluntad de vivir. Si su destino, desde el punto de vista histórico, pertenece a un pueblo y a una raza, moralmente es patrimonio de la humanidad. Allí reside el secreto de su inmortal supervivencia. María es el instinto primario, la impulsión biológica que desemboca en un corazón puro. Es una creación para todos los tiempos y para todos los espíritus, porque la savia de lo eterno busca precisamente las raíces más universales del hombre para subir a convertirse en flores de belleza.

Hay en Isaacs un detalle característico, y es la manera personal y comunicativa camo interviene en la descripción de la naturaleza. No es un realista a secas, o sea, uno de esos escritores que enfocan el paisaje de modo impersonal, como simples fotógrafos, o a ejemplo 
de los turistas despreocupados, que toman apuntes de los parajes pintorescos. Isaacs considera siempre el mundo exterior en relación con su espiritu, y sólo se refiere a aquél para hacer más sensibles las relaciones de esa consonancia interior. La naturaleza no es el escenario de su alma, sino un personaje viviente que participa de la emoción dramática. Impregna las cosas de su propia sensibilidad, y para ello se vale de esa potencia comunicativa de su estilo que nos hace amar y sentir cuanto cae bajo el influjo simpático de su pluma. Los pasajes descriptivos de María serán admirables siempre como esfuerzo pictórico; pero su mayor encanto reside en que nos acercan y ponen de manifiesto el alma de Isaacs, envuelta en los velos del paisaje. La naturaleza es inexpresiva y muda mientras no la toca la inteligencia del hombre. Cosas que antes pasaban inadvertidas, se transfiguran en objetos dignos de consideración con sólo que un artista las consagre espiritualmente. Los pintores nos han revelado la naturaleza, y, gracias a la contemplación de sus cuadros, descubrimos hoy en las cosas muchos matices, expresiones y efectos que sólo el arte podía manifestar. El color de las nubes, los reflejos de agua, las infinitas gradaciones de la luz, etc., nos emocionan más o menos, según sea el grado de nuestra educación estética. Al salir de un museo descubrimos en el mundo acordes y sinfonías de colores que antes no habíamos advertido. El arte educa para la contemplación del universo. $Y$ esto que digo en relación con la pintura se aplica, mayormente, al tratarse de la poesía, o de la literatura en general. E1 genio del poeta nos revela el poder del hombre, afirmó Goethe. Los bellos poemas han hecho patentes los hondos dolores y los fieros heroísmos humanos. Más que los psicólogos profesionales, han sido los alumnos de las Musas quienes han explorado con mayor lucidez los abismos de la conciencia. E1 trágico inglés expone, mejor que todos los textos del mundo, la naturaleza de las grandes pasiones. La acerba melancolía del cantor de "Las Noches" y la árida desesperación de Leopardi fluyeron en poemas que ilustran, con más claridad que las exposiciones científicas, acerca de la tristeza carnal, o del ansia infinita, que hallando muda y ciega a la naturaleza, busca espacio a su vuelo allá donde las constelaciones se encienden y se apagan como nuestra esperanza.

E1 viajero que transita por esta región incomparable experimenta de continuo emociones que lo llevan de la fruición deleitosa y serena, al entusiasmo tembloroso. La visión de la llanura, abierta como 
un amplio regazo para ofrecer todos los dones del trópico, y cuya ondulada extensión muere al pie de montañas azules, sobre las cuales reposan nubes turgentes que sirven de apoyo a la cúpula de zafiro, de donde llueven todos los beneficios de la luz y del viento, es cosa que abre al alma perspectivas insospechadas; en tanto que los plantíos crepitantes, los pacíficos ganados y el ancho río que revuelve en su fondo selvas y nubes, despiertan la codicia del corazón, y dejan que el espíritu se adormezca en la sensualidad de la tierra. Pero si el viajero ha leído a Isaacs, entonces se multiplican maravillosamente sus sensaciones. Todo cuanto había en el paisaje de oculto o fugitivo reaparece ante sus ojos con intensidad luminosa, y como cuajado en moldes eternos. Todo será antiguo y venerable, viviente y alegórico, como en la tierra de los santos. Las colinas tendrán expresión, como los rostros humanos; el soplo del aire pasará como ésas canciones que suelen evocar el ambiente de una época, la emoción de una raza; y en el ruido de las cascadas y de las fuentes se escucharán, mezclados, la voz de la fábula, el sordo arrullo de los amores perdidos y el eco de las antiguas oraciones, que el viento recoge al circular entre los sepulcros.

i Milagrosa potencia del estilo! ¡ Poder infinito del sentimiento! Si Jorge Isaacs no celebra esta tierra en su novela, por haber fijado en otro sitio - supongámoslo brevemente- el escenario de su pasión, ¿creéis que el paisaje del Valle tendría la significación espiritual que adquirió después de publicada María? Otros poetas hubieran podido cantar, y de hecho han cantado con el arpa y con la flauta, la exuberancia de esta tierra, sus bíblicos pastoreos y su mística comunión de aguas y de cielos. A él pertenecen el honor histórico de la empresa y la invención del romance. Realizó la conquista lírica de esta comarca sin más armas que la espada del canto; y después de haberla alinderado con flechas de oro, levantó en el centro una pira de leños aromáticos y puso a arder su propio corazón, en sacrificio expiatorio que perdura todavía.

iEspectáculo extraño y sorprendente para esta edad de hierro! Yo veo a los capitanes de la industria, a los maestros de la técnica contemporánea, a los profesores del materialismo irredento y a los buscadores de oro contemplar, sin lograr explicárselo, aquel holocausto sublime. Comprendo que es muy poco lo que a cierta parte de la humanidad puede expresar ese poema sin complicaciones, ante- 
rior, en setenta años, al psicoanálisis, a la novela proletaria y a la interpretación de los sueños. Se me alcanza igualmente, con cuánta frialdad deben acercarse a esas páginas los biznietos de Góngora y los herederos del habla maquinista que apareció tras la quiebra moral de 1914. Ni al técnico industrial, ni al aprendiz de Freud, ni al mecánico del idioma pueden agradar aquella rusticidad de ambiente, aquel platonismo de la pasión, aquel estilo firme y castizo, que al adoptar el tono alto siempre tiene presentes las raíces follklóricas, $\mathrm{y}$ al descender a la expresión popular y a los dialectos regionales, lo hace con tan subida dignidad que nos recuerda el caso de los dioses helénicos, quienes no perdían el resplandor que emanaba de su cabeza, así ordeñasen las cabras, o labraran vasos de boj, revueltos con los pastores.

No intentaré negar que los gustos cambian, que los géneros literarios han evolucionado, que el arte se ha ido complicando a medida que la historia y la filosofía, las ciencias psicológicas y las sociales le han abierto inesperados cauces y anplisimos terrenos de investigación y de estudio. Tampoco cerraré los ojos ante la evidencia de un hecho indiscutible: que la novela ha ganado tanto en extensión y en profundidad, que ha acabado por resumir en sí todos los géneros de expresión estética, y vastas zonas científicas que antes estaban destinadas al trabajo del médico, del político o del historiador. La novela pretende ser hoy, con razón, más que nunca, síntesis de la actividad humana, y compendio cíclico de todas las culturas. Por otra parte, hechos nuevos como el predominio de las muchedumbres en la vida política de los estados, la omnipotencia de los nuevos Césares, la rebelión de los antiguos siervos de la gleba, etc., han entrado también en el dominio de la invención novelística y le están dando a este género definido hasta hace poco como una ficción recreativa y saludable, ambiente de polémica, intención doctrinaria, alcance sociológico. En nuestra América, por ejemplo, entre los novelistas actuales, unos plantean el problema de la tierra, otros el del caudillaje político, aquéllos el de la explotación indígena y no pocos el de la cuestión religiosa. La novela, y casi pudiéramos decir que la poesía y el teatro, han perdido, pues, con rapidez que no sabemos a dónde nos conduzca, su carácter de invenciones bellas, espirituales y desinteresadas, para convertirse en vehículo de casi todos los problemas que aquejan al mundo contemporáneo y en órganos de propa- 
gación y de contagio intelectual, como pueden serlo el periodismo militante, o el balcón abierto sobre la plaza pública.

Ahora bien: ¿Hasta dónde puede mezclarse el arte con ideas extrañas a su naturaleza y a sus fines, sin perder su categoría estética y su alto linaje de instrumento destinado a medir la potencia creadora del hombre? Problema es éste cuya consideración no nos incumbe por ahora. En todo caso, y la historia de las ideas estéticas así lo demuestra, las obras artísticas que mejor han conservado su integridad y frescura son aquellas cuya concepción obedeció al sólo propósito de crear belleza, revistiendo de forma sensible deleitosa, una de aquellas ideas que Platón llamó puras, eternas y bienaventuradas. Cuando al lado de la concepción pura hizo intervenir el creador ideas circunstanciales de otro orden, atañederas a la política, o al elemento decorativo y pintoresco de un siglo, el tiempo mismo se encargó de abultar y volver luminoso el núcleo estético de la obra, dejando que lo demás se desprendiera como los bordes quebradizos de una hoja. En Lope y Cervantes ha caducado todo lo temporal, y sólo se destaca la parte incontaminada y universal de su genio. Las alusiones políticas de la Divina Comedia resultan pálidas ante el verso de oro y de zafiro con que Dante, desde una montaña del purgatorio, saluda al mar distante, franjeado y rico de ondulaciones como una bandera. ¿Por qué? Porque el arte es celoso de su pureza $y$, a diferencia de los metales finos, la liga lo rebaja y deprecia. De veinte años a esta parte hemos visto morir sinnúmero de escuelas artísticas que habían nacido originariamente impuras. En cambio, la crítica ilustrada y el instinto popular han tornado, con admiración y respeto, hacia formas mucho más universales y simples de la sensibilidad. $Y$ es esto, a pesar de las consideraciones hechas arriba, lo que ha vuelto a darle a la novela de Isaacs calor y palpitación de actualidad. Maria es creación pura del sentimiento. No obstante contener todo lo precario y circunstancial de una época, la alta inspiración de la obra y la calidad de su estilo, rompen toda limitación de tiempo $\mathrm{y}$ de escuela, para proyectarse sobre un plano de actualidad eterna. María, como todas las grandes obras del ingenio humano, más que el inventario intelectual de un país pertenece, primeramente, a la biografía particular de cada hombre, $y$, después, a la enorme y contrastada historia de la humanidad. ¿Quién no les confió a las flores el secreto de una pasión oculta? ¿Quién no vió eclipsarse después, tras 
la amargura del conocimiento, aquella cándida imagen que se alimentaba de nuestra propia inocencia? Seamos sinceros, heroicamente sinceros para reconocer que todos llevamos algo de viudez por esa niña candorosa, que surge en mitad de nuestra adolescencia, se oculta en los años del derroche vital, y nuevamente aparece en el límite de la madurez, semejante a esas nubes de verano que se visten de oro por la mañana, y vuelven a ostentar por la tarde el mismo ropaje, pero ya suspendidas sobre un horizonte solemne que se prepara al advenimiento de la noche.

Hay que prevenirse contra ese Isaacs de cartulina postal que nos han dado algunos al rodear al poeta de todo el decorado romántico de la época. Dice un biógrafo suyo que una dama bogotana le obligó a que se retratase con la escopeta en una mano y un ramo de azucenas en la otra. La fotografía tuvo fortuna entre las personas sensibles, pero causó daño al novelista. Isaacs fué un tipo viril. Basta observar los retratos que de él nos quedan para fallar inmediatamente sobre el temple de su carácter. Aquella frente espaciosa y cuadrada, de la cual arranca la nariz recta y fina; aquellos ojos penetrantes y agudos, velados por las cejas espesas; aquella boca expresiva sobre la cual cae un amplio bigote de seda; aquella mandíbula descarnada, de contornos patricios, todo denuncia al varón de ánimo fuerte y de largos alientos para toda clase de empresas. La bóveda craneana, cubierta de hermosos cabellos echados hacia atrás, domina valientemente el resto de la fisonomía. Noble rostro de hidalgo, apenas ensombrecido por una leve nostalgia que sienta admirablemente a su palidez nativa. Era ameno y espontáneo en la conversación; solía entusiasmarse hasta la elocuencia cuando discurría sobre asuntos que le eran particularmente agradables. Gustaba de los pocos y escogidos amigos. Su vida familiar fué intima y apacible. Delante de la esposa inteligente, que cuidaba de que no se apagase la rústica luz de las veladas nocturnas, terminó su novela y corrigió las pruebas de imprenta. Escribió mucho: novelas, dramas, poesía. Acaso le molestaban las diarias preguntas de que era objeto en relación con la existencia real de María. Nunca quiso aclarar el enigma, sin duda porque no lo había. Pudo alarmarse también al considerar el ambiente de falso sentimentalismo de que empezaban a rodearse su persona y su obra. De toda la América le llegaban cartas elogiando la novela. María, la muchacha del Cauca, había desatado lágrimas y en- 
tusiasmo en todos los pueblos de habla hispana. Pronto conquistaría a los extraños. ¿Qué más desear? Vivía en Ibagué, pobre y envejecido; pero la gloria subía, como una rosa de luz, por encima de los montes de Tolima, para bañar de suaves resplandores su cabeza entrecana. Maria, como una virgen guerrera, estaba ganando para su padre las últimas y definitivas batallas de la inmortalidad.

Fué Isaacs no sólo un romántico de la literatura, sino un romántico de la acción. Niño aún conoció la vida azarosa de los campamentos militares. Más tarde encabezó revoluciones civiles, y hubo de redactar panfletos políticos que, según dicen, fueron quemados públicamente. Muerto su padre, el caballero inglés de origen judío de quien había heredado ideas tradicionalistas, y rematada la fortuna por los numerosos acreedores, se hizo "radical". Asistió al parlamento y fué orador de fogosos arrebatos. En alguna ocasión tuvo que enfrentarse a las iras populares. Practicó el periodismo, fué negociante, viajero y explorador. En un país sin ferrocarriles, sin carreteras, y sin más caminos que los del cielo, como decía Fígaro, todas sus andanzas las realizó a lomo de bestia, por vericuetos intransitables, por montañas medrosas pobladas de bandoleros y por climas letales que acabaron con su extraordinario vigor físico. Buscó el oro incansabiemente, no por sordidez de avaro, sino para volver a su prístina posición de hombre rico, y acaso para rescatar la casa de sus padres, venida a manos extrañas, y morir allí donde había amado. Pero el dinero huyó siempre de sus manos, tras envolverlo en litigios dificultosos. Cansado de perseguirlo a través de las combinaciones comerciales, hurgó en los propios yacimientos del veleidoso metal, y así lo vemos en la Goajira, hecho minero y explorador, conviviendo con los salvajes, recorriendo las áridas costas y los pantanos sombríos, febricitante, unas veces; al borde de la muerte, otras, pero siempre con la obsesión del petróleo y de la hulla que debían de redimirlo económicamente. No pudo ser, porque escrito está que el genio viva desposado con la pobreza, y que la mano destinada a recibir la dádiva de la eternidad ignore el peso de la moneda con que el hombre paga a los esclavos del tiempo. Regresó Isaacs a su retiro del Combeina, con la sangre envenenada por el maléfico insecto de los trópicós. Su palidez se tornó amarillenta. La fiebre intermitente aceleraba el ritmo de sus arterias, consumía sus huesos, excitaba la llama de su cerebro. Bajo el influjo de la calentura palúdica es seguro que re- 
cordase muchas veces la escena remotísima que dió origen a su celebridad literaria. Vamos a evocarla rápidamente.

Es en Bogotá, en mayo de 1864. Calles empedradas; balcones. de madera que, en los días de fiesta, se cubren de mantillas y abanicos; en cada esquina un farol melancólico cuya luz queda anulada por completo en las noches de luna, horas en que los cerros vecinos destellan pálidamente como montañas de mármol. Campanas y vocerío de feria en el centro de la ciudad; más allá, en las afueras, tranquilos bosques de eucaliptus; que se coronan de niebla por la mañana, y en las tardes de viento perfuman la sabana como incensarios vegetales. La vida discurre como fuera del tiempo. En los hogares hay tertulias que se prolongan hasta altas horas de la noche, $y$ en las que se baila, se recitan versos y se toma la generosa bebida a que alude don Andrés Bello en un verso milagrosamente acentuado. Todo esto acontece bajo el resplandor que vierten, desde lo alto del techo "arañas" de cristal, que multiplicando y descomponiendo su propia luz en los prismas colgantes de que están adornadas, semejan arbustos incandescentes llenos de mariposas de colores. En los espejos de Venecia se reflejan las señoras de alto busto y de moño con alfileres, y los caballeros de pantalón ajustado, como estampas iluminadas de la época, en el fondo de una galería romántica. Pero no es a un salón de éstos, sino a un cuartucho desarreglado, a donde entran ahora los señores de esta verídica historia. Miradlos: Capa española, paraguas y sombrero de copa. Todo rígidamente oscuro. Tienen aire de conjurados y de galanteadores. Muchos se parecen al Zorrilla y al Espronceda que figuran en el cuadro de "El Parnasillo", pintado por Antonio Gisbert. En primer lugar Vergara y Vergara, un puro hidalgo español con dejos de humor criollo. Vienen luego Samper, el polígrafo; Marroquín, el castellano de la sabana; Carrasquilla, el educador; Aníbal Galindo, el internacionalista y traductor de Milton; Diego Fallon, en quien había, como en Isaacs, mezcla de razas y diversidad de aptitudes; autor de un canto purísimo, digno de aquel arcángel rebelde cuyo cuerpo de náufrago mereció funerales homéricos en una playa de Italia; Camacho Roldán, ilustre repúblico, periodista fogoso, hombre de nobilísimo carácter; Manuel Pombo, de aristocráticos modales, de rápido y espontáneo talento; José María Quijano Otero, Rafael Samper, Ricardo Becerra, Ezequiel Uricoechea, Teodoro Valenzuela, Próspero Pereira Gamba. Casi todos estos 
caballeros - y es de advertir que en la presente histórica reunión no figuran ni Guarín, ni Ricardo Silva, ni Eugenio Díaz, contertulios habituales - cultivan una literatura pintoresca, a veces casera, pero impregniada de color local, de ambiente criollo, entre mundana y campesina. Unos son paisajistas afortunados; otros, pintan "naturalezas muertas"; no faltan quienes se divierten haciendo rápidos y originales dibujos de algunos rincones de la citudad, y de sus personajes más populares. Existe también el escritor que rompe los estrechos límites del cuadro de costumbres y se ensaya, con brioso realismo, en la novela. He nombrado a don Eugenio Díaz. En medio de esta familia espiritual, tan rica en talentos, tan variada en disciplinas, $\tan$ generosa en entusiasmos, tan inagotable en estímulos, aparece Isaacs. Tiene un poco más de veinte años. Lee unos cuantos versos olorosos a su provincia nativa, algunos romances montañeses, unos pocos poemas de amor. Eso basta para cautivar al auditorio. Estallan las palmas, y el futuro autor de María se abraza, desde entonces, a esa cruz de expiación y de honor en que vendrá a convertirse su destino espiritual. Quizás entonces, y envuelto en la primera ráfaga de gloria, escuchó el aleteo del ave oscura que atravesando más tarde, con vuelo fatídico, su poema, caerá muerta sobre el sepulcro de Maria, para trocarse en la alondra jubilosa, que canta la juventud eterna del amor y del genio.

No sé hasta dónde pudo tener Isaacs conciencia de su obra. La historia del Homero sin pupilas puede no ser más que un símbolo acerca de esta misteriosa ceguedad del genio, que ignora muchas veces su propia capacidad, o se lanza por caminos de que suele apartarse después el consentimiento de los hombres. En el centro de ese disco radioso, que ilumina los cielos de la inteligencia y proyecta su resplandor hasta los más apartados horizontes de la historia hay, como en el sol, manchas oscuras y sectores opacos que ocultan, a los grandes creadores, la trascendencia de su obra. Por otra parte, las aflicciones de la vida, toda esa miseria presente que se palpa, se conoce y se vive, embotan frecuentemente la sensibilidad, llevan su aire maligno hasta las más alegres moradas de la imaginación, y el artista, en un momentáneo eclipse de su espíritu, llega a confundir a los hijos de su genio con los engendros de su dolor: a la dádiva del cielo con el ingrato pan de la tierra; al efímero grito humano con las voces del inmortal alumbramiento. ¿Confusión de la vida! 
; Miseria del destino! ; Fatalidad de la inteligencia! Muere el hombre creyendo que su espíritu quedará para siempre atado a las miserables circunstancias de su existencia; y he aquí que el tiempo y el silencio, invisibles obreros de la tumba, comienzan a purificar la memoria del genio: rompen las ataduras y vendas de la muerte, destruyen toda escoria adherida a la carne mortal, queman los trapos del sepulcro, y, del árido copo de cenizas, elevan la imagen inmortal al cielo de la memoria humana.

Ignoro si Jorge Isaacs tuvo el presentimiento de este hecho, o si creyó, por el contrario, que su carne y su genio rodarian al fondo de la pálida urna. Creo más en la evidencia de esta última suposición. Tampoco se me alcanza si llegó a valorar cabalmente la grandeza de su siglo. Probablemente no. Las discordias políticas y el humo de los campamentos pudieron entorpecer su visión de los hechos y de los hombres. Por otra parte, su orgullo de raza lo apartaba discretamente de sus contemporáneos, con muchos de los cuales había tenido choques personales y duelos de palabra y de pluma, circunstancias todas que en este país crean enemistades mortales. No pudo, pues, englobar, dentro de una visión ecuánime, el granđioso panorama de su tiempo. Personajes de aventajada talla para nosotros hubiéron de parecerle odiosos pigmeos; $y$, grandes hombres, modestos ciudadanos de cuyos nombres ya nadie se acuerda.

Sin embargo, la época de Isaacs, descontadas las heroicas jornadas del movimiento emancipador, fué tan grande en obras y tan fecunda en ideas, que bien merece llamarse "edad de oro" del pensamiento americano. Durante esa última mitad del siglo xix, más de medio centenar de figuras representativas se mueven dentro del panorama de la nación, crean valores perdurables de cultura en todos los ramos de la actividad humana. Causa pasmo la vitalidad de una raza que, después de haber forjado una generación de apóstoles y precursores para entregarlos al cadalso, alista inmediatamente otra, de generales, estadistas y soldados, que consolidan la obra anterior, y organizan el caos de los primeros tiempos republicanos, para lanzar, a continuación, un nuevo contingente de pensadores, humanistas y poetas, que cubren literalmente de palmas académicas y de rosas apolíneas la roca ennegrecida que sirvió de fundamento al altar de la patria; a cuyo pie se habían librado las batallas libertadoras, y que sintió brotar, de sus flancos despedazados, los primeros arroyos de púrpura fecundante. 
i Años generosos, que elevaron la historia de Colombia al nivel de las edades helénicas! La figura de Isaacs, así enmarcada, gana considerablemente en magnitud, porque tuvo, como rivales y compañeros, a personajes hercúleos, que se daban la mano con altos representantes de la cultura europea. Literariamente, fué testigo. Isaacs de la aurora romántica, presenció el movimiento realista, pudo contem. plar el glorioso renacimiento de los estudios clásicos, y escuchó los primeros clarines de la vanguardia modernista. A su espalda resuenan el arpa délirante de José Eusebio Caro, la lira heroica de don Julio Arboleda, la trompa y el salterio de José Joaquín Ortiz. Al lado suyo canta Pombo con voz universal, juntando, en acorde arrollador, la cuerda de cobre de las canciones populares, la cuerda de plata del erotismo cósmico, la cuerda de oro de la meditación filosófica; plantea Núñez su duda en ásperos versos, que son como el camino de piedra de la especulación poética; deja oír Gutiérrez González su flauta y su tambor, convidando a la siembra y a la cosecha. Un poco más allá erige Caro sus hombros de piedra; en uno de ellos sostiene el Orbe de las humanidades; en el otro, el escudo de la República. Cuervo, por su lado, narra la génesis del idioma, la peregrinación y muerte de los vocablos, las dinastías de la palabra. Es el Moisés de las lenguas. Pero, ¿a qué seguir la enumeración? Todos los géneros literarios y las disciplinas espirituales tienen en ese tiempo quien las cultive y las ilustre. La República es taller, universidad y campamento. Bajo el ático frontón de la nueva Atenas del trópico, Mercurio, Marte y Minerva, en traje de paisanos, alternan sus oficios y sus emblemas. E1 poema épico, la oda patriótica, el romance, la crónica y la leyenda; la sátira y el epigrama; la noble y ejemplar historia, al modo de Tácito o de Tito Livio; los estudios sociales, políticos y económicos; la polémica filosófica y religiosa; las cuestiones filológicas y gramaticales; la oratoria popular, la forense y la parlamentaria; el cuadro de costumbres, la novela, el drama y la comedia; la crítica comparada; las disciplinas humanísticas, la investigación científica, la oratoria religiosa, la poesía mística, el artículo de periódico: tal es el inventario intelectual de la época; tales son los cauces por donde fluye la inquietud sentimental de esas generaciones; tales son las empresas que coronan de escudos y de torres la ancha muralla que nos separa de ese siglo.

Preciso es admitir, que mucha parte de esa producción intelectual ni alcanzó formas excelentes, ni rompió los términos de su época. 
El mérito y la gloria de Isaacs consisten en haber salvado integramente, para todos los tiempos, el valor de una obra escrita en años en que la preceptiva de la escuela literaria imperante, la reacción criolla y el nacionalismo estético, limitaban con frecuencia el concepto de la creación artística, cerrando los caminos de lo universal y humano. Isaacs tuvo el buen cuidado de distinguir entre el romanticismo de escuela, que apenas implicaba una reacción contra las rigideces académicas, contra la literatura de imitación y erudita, contra el concepto neo-pagano de la sociedad y de la vida, y ese otro romanticismo eterno - modalidad sustancial del espíritu humanoque en fin de cuentas no es más que un retorno a las anchas y generosas aguas de la vida. Ese romanticismo abre los diques a todas las fuerzas expansivas y creadoras del espíritu; comulga con la naturaleza, de la cual extrae imágenes siempre frescas y símbolos perdurables; se reintegra al suela nacional, cuyas leyendas y tradiciones exalta; baja hasta el pueblo, de donde extrae la expresión castiza y espontánea; no desdeña el trato con el vulgo, de quien suele aprender el modismo típico, y acaba por remontarse a la esfera metafísica, proponiendo los torturantes problemas de Dios y del hombre, del cielo y de la tierra, del tiempo fugitivo y de la eternidad inalterable. Hálitos puros de ese romanticismo animan la obra de Isaacs, la preservan del tiempo, la colocan por encima de las modas literarias y le otorgan los dones de la juventud perpetua, supremo galardón que sólo está destinado para los hijos del espíritu.

He querido evocar a Isaacs viviente, $\mathrm{y}$ acaso no haya logrado ofrecer más que un torpe boceto del escritor. Perdonadme. Vamos a suponer ahora que el autor de Maria, semejante a las sombras meditabundas que halló Virgilio en la llanura subterránea, recorre esta comarca y transita por las calles de la ciudad natal. Sosegadas en su pecho las pasiones políticas; extinguidas, bajo la sombra de las tumbas, las enemistades y malquerencias que lo rodearon; glorificada su novela en todas las naciones de habla hispana; el poeta contempla a Cali, su pueblo amado hasta la cólera, como amaban los profetas bíblicos, convertido en urbe poderosa, que recibe directamente del mar todos los beneficios de la civilización. Admira las fábricas de cemento y acero, las avenidas asfaltadas, los puentes de hierro, los parques, húmedos siempre y recortados como cabelleras femeninas, los motores resonantes, los edificios industriales, los teatros y los 
Bancos, en fin, todo el ornamento de la civilización contemporánea, y su corazón se inflama de gratitud por los hombres. Mira hacia el valle y percibe la misma luz cayendo en lentejuelas impalpables sobre el espejo de los ríos, sobre el alto cáliz de las palmeras, sobre los flancos y hondonadas de las colinas distantes, esculpidas como tronos y como altares para sostener la magnificencia del cielo. Recuenta los pueblecitos conocidos, los caminos habituales, los árboles preferidos de su corazón y las buenas hierbas domésticas. Alli están el cedro patriarcal, el chiminango frondoso, la ceiba hospitalaria, el cámbulo esbelto, la jigua perfumada, el carbonero de flor purpúrea, el naranjo nupcial, el tamarindo melancólico, la saludable yerba-buena, y el "quereme" que perfuma las ropas. Vuelven a extasiarlo, con renovada nostalgia, los crepúsculos del Cauca, solemnes como la agonía de un pontífice, dorados como el fondo de las catedrales, trágicamente raudos como el incendio de una flota aérea. Su imaginación se llena de fervor delante de esa naturaleza, siempre fiel a sí misma, y, no obstante, espejo de perpetuas renovaciones. Pero hay un lugar, amado para siempre, a donde el poeta se dirige, venciendo los primeros declives de la sierra. Avanza. Ya escucha el rumor de su espumoso Zabaletas, de su claro Amaime. Viento de eternidad le trae aromas de rosales, efluvio de azucenas. $\mathrm{El}$ eco de sus pisadas anuncia en las habitaciones desiertas que se acerca el antiguo dueño: la sombra de Jorge Isaacs, coronada de laurel, penetra en la casa de sus padres ... iLo demás es silencio!

Rafael Maya, Bogotá. 
